\title{
Amyloid $\beta$-Targeted Inhibitory Peptides for Alzheimer's Disease: Current State and Future Perspectives
}

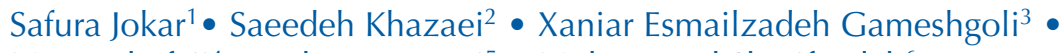 \\ Mona Khafaji ${ }^{4} \bullet$ Behnam Yarani $^{5} \bullet$ Mohammad Sharifzadeh $^{6} \bullet$ \\ Davood Beiki ${ }^{7} \cdot$ Omid Bavi ${ }^{8}$ \\ ${ }^{1}$ Department of Nuclear Pharmacy, Faculty of Pharmacy, Tehran University of Medical \\ Sciences, Tehran, Iran; ${ }^{2}$ Department of Pharmaceutical Biomaterials, Faculty of Pharmacy, \\ Tehran University of Medical Sciences, Tehran, Iran; ${ }^{3}$ Colloids and Polymers Physics Group, \\ Particle Physics Department, Universidade de Santiago de Compostela, Santiago de \\ Compostela, Spain; ${ }^{4}$ Institute for Nanoscience and Nanotechnology, Sharif University of \\ Technology, Tehran, Iran; ${ }^{5}$ Division of Nanobiotechnology, Department of Life Sciences \\ Engineering, Faculty of New Sciences and Technologies, University of Tehran, Tehran, Iran; \\ ${ }^{6}$ Department of Toxicology and Pharmacology, Faculty of Pharmacy; Toxicology and Poisoning \\ Research Centre, Tehran University of Medical Sciences, Tehran, Iran; ${ }^{7}$ Research Center for \\ Nuclear Medicine, Tehran University of Medical Sciences, Tehran, Iran; ${ }^{8}$ Department of \\ Mechanical and Aerospace Engineering, Shiraz University of Technology, Shiraz, Iran
}

Authors for correspondence: Omid Bavi, Department of Mechanical and Aerospace Engineering, Shiraz University of Technology, Shiraz, Iran. Email: o.bavi@sutech.ac.ir; Davood Beiki, Research Center for Nuclear Medicine, Tehran University of Medical Sciences, Shariati Hospital, North Kargar Ave. 1411713135, Tehran, Iran. Email: beikidav@tums.ac.ir Doi: https://doi.org/10.36255/exonpublications.alzheimersdisease.2020.ch3

\begin{abstract}
Alzheimer's disease is the most common irreversible neurodegenerative disorder. To date, there is no cure for Alzheimer's disease. While multiple pathological mechanisms have been proposed for the onset and progression of Alzheimer's disease, the hypothesis that attracted much attention is the amyloid hypothesis. The senile plaques that accumulate in the brain of Alzheimer's disease
\end{abstract}

In: Alzheimer's Disease: Drug Discovery. Huang X (Editor). Exon Publications, Brisbane, Australia. ISBN: 978-0-6450017-0-9; Doi: https://doi.org/10.36255/exonpublications.alzheimersdisease.2020 Copyright: The Authors.

License: This open access article is licenced under Creative Commons Attribution-NonCommercial 4.0 International (CC BY-NC 4.0) https://creativecommons.org/licenses/by-nc/4.0/ 
patients are predominantly composed of beta amyloid (A $\beta)$. A $\beta$ deposition in the brain is thought to occur years before the emergence of clinical symptoms. The overproduction, aggregation, and fibrillation of $A \beta$, combined with reduced clearance, eventually lead to amyloid plaque formation and subsequent neurotoxicity. Hence, inhibition of $A \beta$ aggregation and the promotion of $A \beta$ clearance have been actively explored as therapeutic strategies for Alzheimer's disease. This chapter provides an overview of the current knowledge on one such strategy, A $\beta$-targeted inhibitory peptides.

Keywords: $A \beta$ aggregation in Alzheimer's disease; biopanning; inhibitory peptides for Alzheimer's disease; peptide-nanostructure conjugates; peptidomimetics

\section{INTRODUCTION}

Alzheimer's disease is an age-dependent disorder that is the fifth leading cause of death in people aged 65 years and older. It is estimated that over 50 million people worldwide suffer from Alzheimer's disease, and this figure is set to increase to 152 million by 2050 with a financial burden of 1.1 trillion US dollars by 2050 (1-3). Several hypotheses, including the amyloid, cholinergic (4), and Tau protein hypotheses have been proposed to explain the pathophysiology and etiology of Alzheimer's disease (5). Because of the presence of $A \beta$ in the brain tissue, cerebrospinal fluid, and plasma, the amyloid cascade hypothesis is the most widely accepted. The amyloid cascade hypothesis states that neurodegeneration in Alzheimer's disease is the result of amyloid plaque and neurofibrillary tangle formations $(6,7)$. The overproduction, clearance failure, aggregation, and fibrillation of $A \beta$ eventually leads to amyloid plaque formation. These factors also contribute to neuroinflammation and cell death. A $\beta$ deposition in the brain is likely to be the first pathological incident that occurs years before the emergence of clinical symptoms. A $\beta$ is produced through the proteolytic cleavage of the amyloid precursor protein (APP), a transmembrane glycoprotein, which is made up of a cytoplasmic domain with 55 amino acids and a long extracellular domain with 590-680 amino acids (8). APP cleavage by the proteases $\beta$ - and $\gamma$-secretases produce A $\beta$ fragments of varying size depending on the cleavage site (9), of which $A \beta_{40}$ (about $90 \%$ ) and $A \beta_{42}$ (about 5-10\%) are the most prevalent (Figure 1). A $\beta_{42}$ is more toxic than $\mathrm{A} \beta_{40}$. After production, the $\mathrm{A} \beta$ peptides aggregate to form amyloid deposits. There are different aggregation forms such as low molecular weight oligomers, protofibrils, as well as mature fibrils that eventually come together to form amyloid deposits in the brain parenchyma and cerebrovascular spaces $(10,11)$.

Therefore, inhibition of $A \beta$ aggregation and the promotion of $A \beta$ clearance have been investigated as therapeutic strategies for Alzheimer's disease. Some of these strategies include the use of metal chelators (12), peptides (13), organic molecules (14), and biomolecules $(15,16)$. Peptides are considered a better option than small molecule-based compounds because of their high affinity for $\mathrm{A} \beta$ and low toxicity (17). Although natural amino acid-based peptides are effective inhibitors of $A \beta$ aggregation, they are prone to faster enzymatic degradation and show a tendency for self-assembly into fibrils during administration (15). To overcome these problems, modified peptides have been generated (18) with 


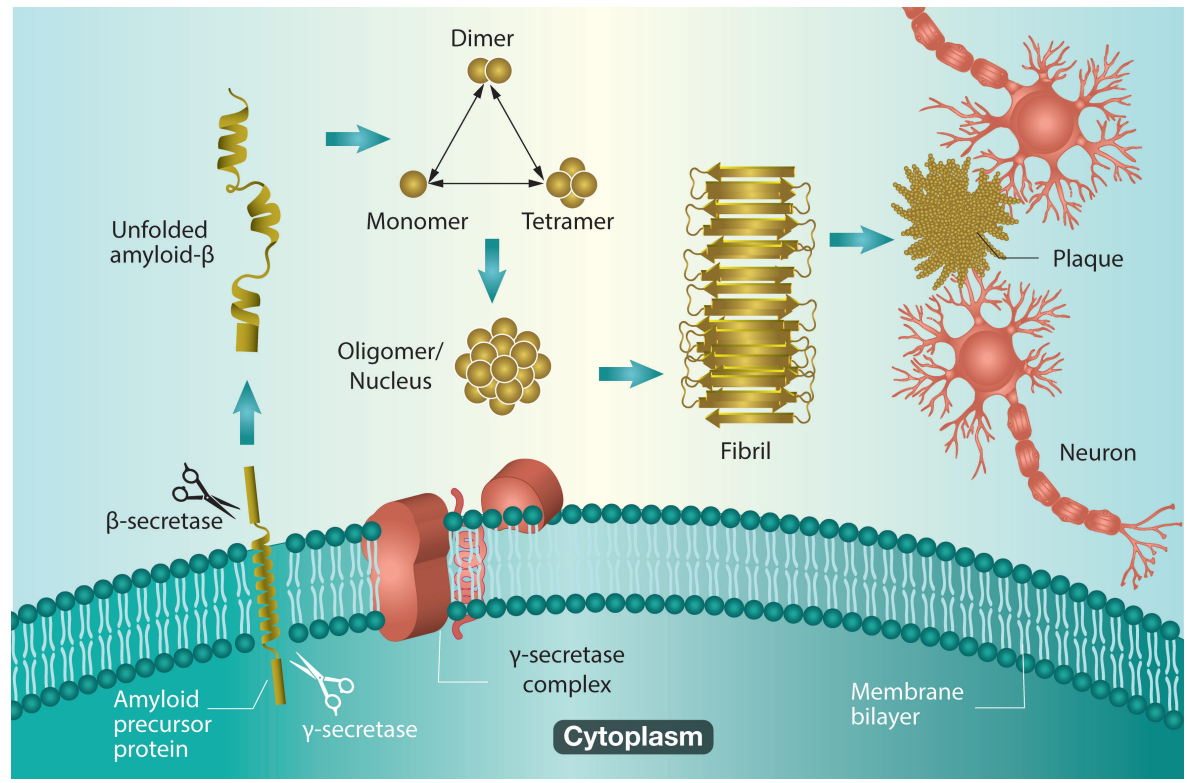

Figure 1. Amyloid- $\beta$ fibrillation and neuronal damage. First, amyloid precursor protein is cleaved by $\beta$ and $\gamma$ secretases, respectively. A peptide fragment of 39-42 amino acid is formed depending on the site of cleavage. After cleavage, $A \beta$ monomers start to self-assemble to form soluble toxic aggregates, and finally into insoluble fibrils, which subsequently cause synaptic dysfunction and neuronal death.

D-amino acids, retro-inverso cyclization, fluorination, as well as N-methylation of the ester bond (19). With this knowledge, peptides could be potential candidates for inhibiting $A \beta$ conformational transitions, self-assembly, and toxicity against neurons, and promotion of the pathways of the nontoxic fibrillation and early diagnosis of Alzheimer's disease (20). This chapter provides an overview of the therapeutic potential peptides as $A \beta$ aggregation inhibitors.

\section{PEPTIDIC INHIBITORS}

Luhrs and co-workers first experimentally described the structure of the $A \beta_{42}$ fibril (Figure 2, right) (21). At least four specific structural sites for interaction have been identified on the A $\beta$ fibril (22): (i), hydrophobic regions of Ala30Val36, and Leu17-Ala21 residues from the $C$ and N-terminal $\beta$-sheets respectively; (ii), hydrophilic part using electrostatic interactions between Asp23 and Lys28 residues; (iii), central cleft in the interior of the U-shaped turn; and (iv), Glu22 ladder between the side chains of the Glu22 residues of the adjacent $\beta$-strands (Figure 2, bottom right). The formation of the salt-bridge between Asp23 and Lys28 is an essential $\beta$-sheet conformation stabilizer. Moreover, it might stimulate the oligomerization of $A \beta$ via stabilizing the Val24-Asn27 turn (23). The hydrophobic residue of Met35 in the C-terminus domain could support 


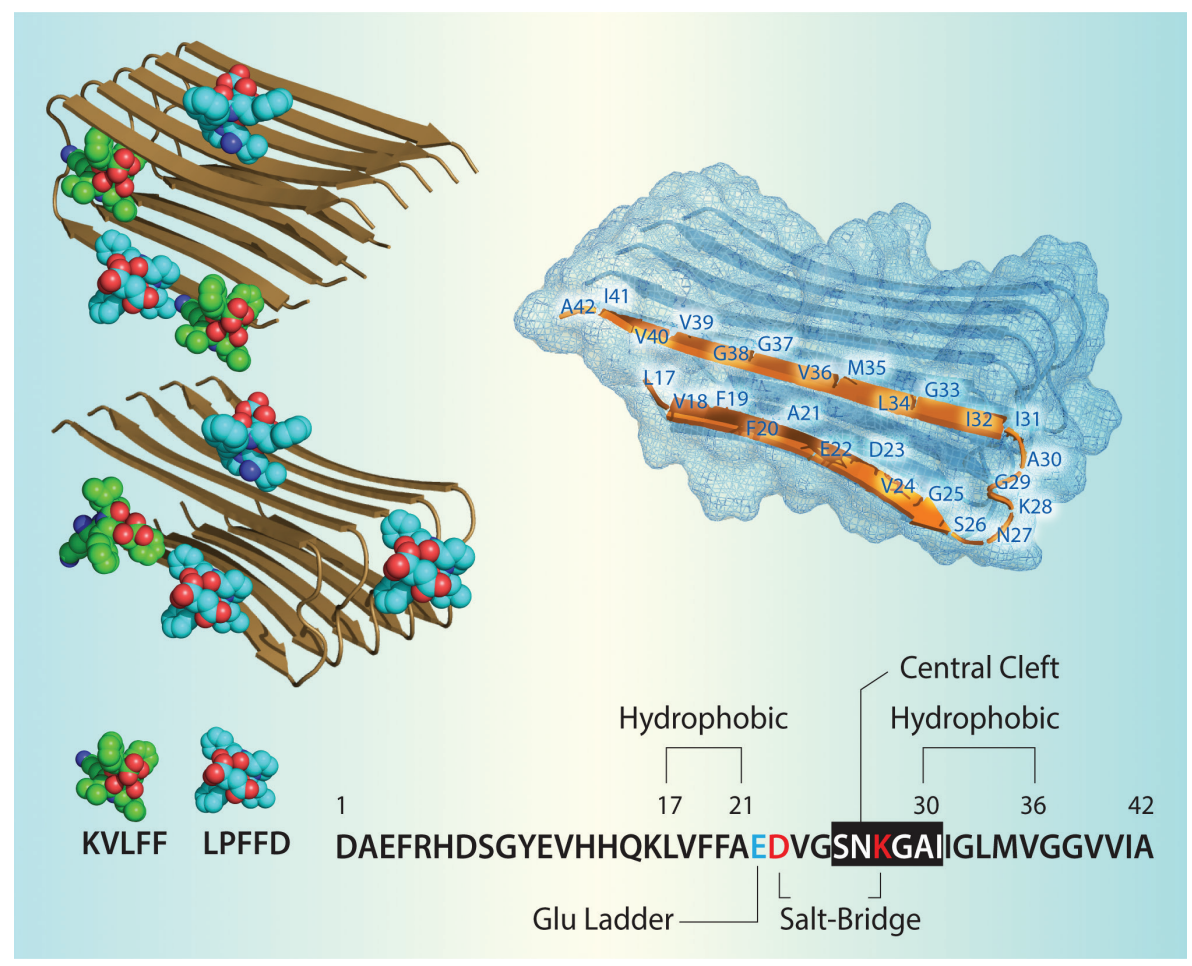

Figure 2. The structure of $A \beta$. Right, schematic of the $A \beta_{42}$ amyloid fibril. Left, binding sites of inhibitory peptides of LPFFD and KVLFF on $A \beta_{40}$ fibril.

fibril stability by hydrophobic interactions. The Met35 binding site can potentially inhibit protein-protein interactions and prevent amyloid fibril formation (24). These sites are probably critical regions in the initiation of $A \beta$ nucleation, conformational transition promotion, and fibril formation. The residues ${ }^{16} \mathrm{KLVFFA}^{21}$ (Figure 2) of the central hydrophobic core (CHC) region is a critical nucleation site, or self-recognition sequence. The Ile4l and $\mathrm{Ala}_{42}$ residues can modulate $A \beta_{42}$ oligomer formation (25) by interacting with the $\mathrm{N}$ and $\mathrm{C}$-terminus of $A \beta_{42}$ (26). Figure 2, left, shows the binding sites of the most common inhibitory peptides, such as LPFFD and KVLFF, on the $A \beta_{40}$ fibril structure.

Peptide inhibitors are generally divided into $A \beta$-based peptide inhibitors and non-A $\beta$-based peptide inhibitors. A list of select $A \beta$ inhibitory peptides are presented in Table 1.

\section{A $\beta$-based peptide inhibitors}

These are based on the structure of the C-terminal fragments (CTFs) and the $\mathrm{CHC}$ sequences of the $A \beta$ peptide. They bind to the $A \beta$ peptide at specific sites and prevent its assembly into amyloid fibrils. Peptides consisting of D-enantiomeric amino acids exhibit greater stability against proteases and show a higher binding 


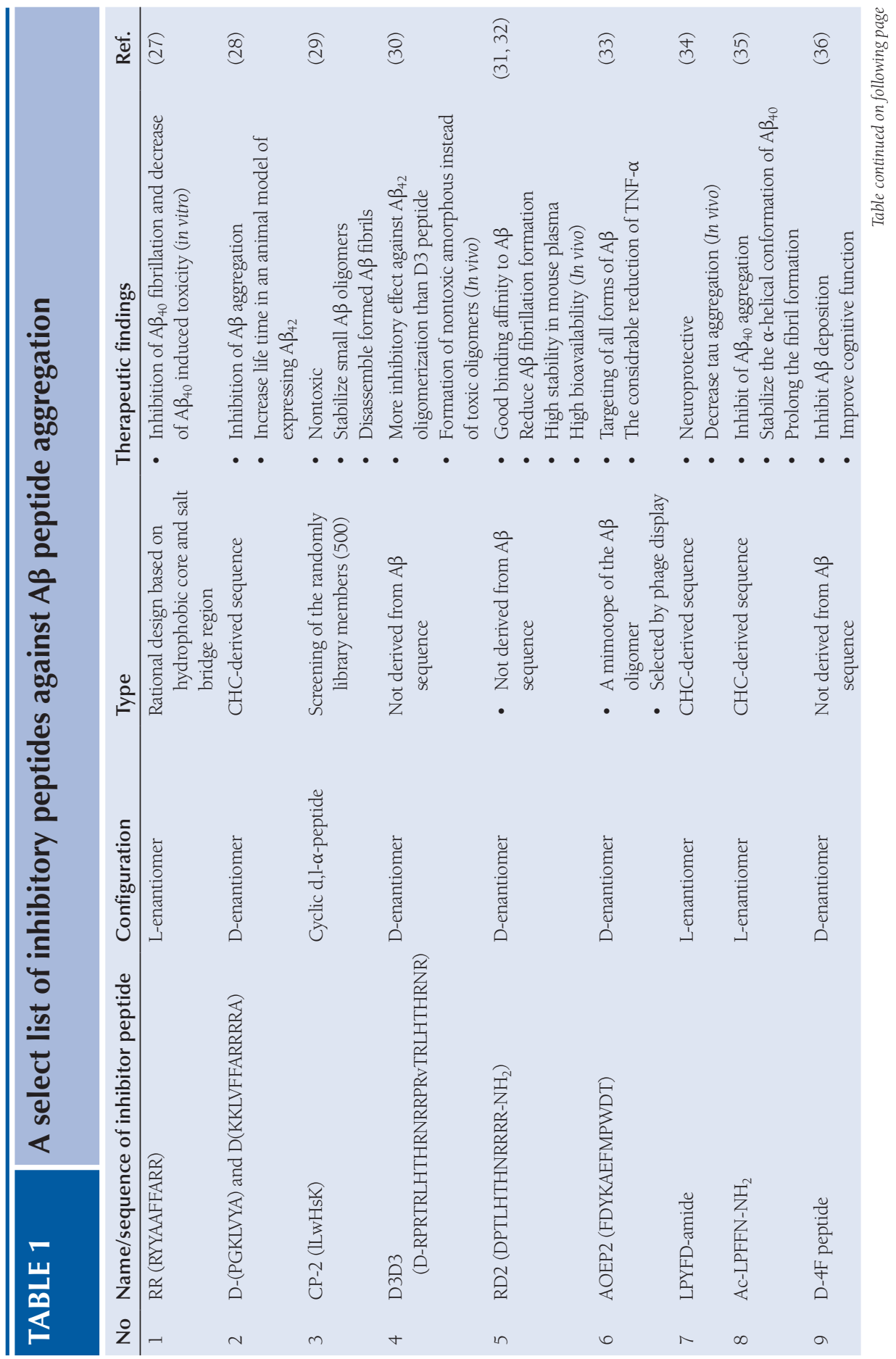




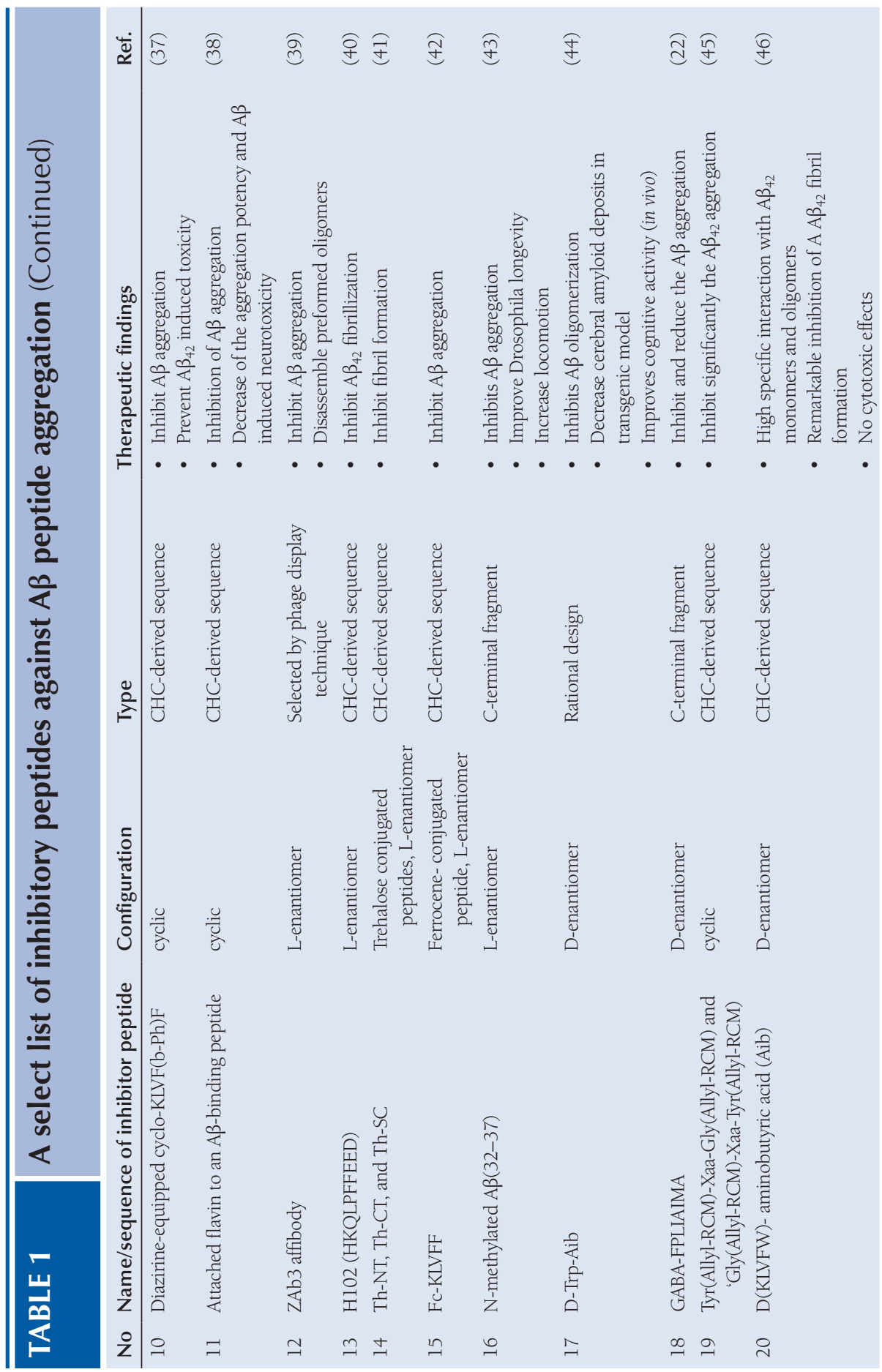


affinity for $A \beta$ compared with their L-enantiomeric counterparts. Moreover, $D$-peptides inhibit $A \beta$ aggregation in animal models (28). Retro-inverso peptides are a special class of modified peptides that contain D-amino acids and reversed $\mathrm{NH}$ and $\mathrm{CO}$ groups in the peptide bonds. These peptides could keep the same spatial position in the side chain of the residues and preserve the desirable 3D structure compared to unchanged L-peptides (47). They also displayed advantages in terms of $A \beta$ aggregation inhibition, higher proteolytic stability, lower selfassembly, and better blood-brain-barrier (BBB) permeability when compared with L-peptides in an animal model $(48,49)$. Fluorinated hydrophobic valine or phenylalanine in the LVFFA-based peptides can considerably delay the formation of $A \beta$ aggregation. Fluorinated amino acids can also inhibit $A \beta$ aggregation (50). Modification of amide functional groups with a methyl group is another strategy in the development of new inhibitors. N-methylated amide groups could enhance the peptide's solubility in aqueous solutions and decrease $A \beta$-induced toxicity. Cyclic peptides have a higher inhibitory activity than acyclic derivatives (51). Because of their high enzymatic resistance, they are degraded slowly. Residues of lysine and glutamic acid have been known to be effective stabilizing and enhancing agents of $A \beta$ fibrillation due to their ability to improve surface tension. In contrast, arginine residues have been reported as aggregation inhibitors or destabilizers (chaotropes) (52).

The ${ }^{16} \mathrm{KLVFF}^{20}$-based peptides play a crucial role in disrupting $A \beta$ aggregation by binding to full-length $A \beta$ peptides and preventing fibril formation $(53,54)$. Ac-LVFFARK-NH2 (LK7), designed by adding arginine and lysine to KLVFF, induced a dose-dependent inhibition on $A \beta_{42}$ fibrillation; however, it was cytotoxic due to high self-assembling properties (55). When conjugated with poly (lactic-co-glycolic acid) nanoparticles (NPs), the LK7-PLGA-NPs complex resulted in the elimination of the LK7 self-assembly feature while inhibiting $A \beta_{42}$ fibrillation (55). Binding $\beta$-cyclodextrin to LK7 (56) improved LK7 peptide solubility, inhibited its tendency to self-aggregate, improved its binding to $A \beta$, and inhibited $A \beta$ aggregation. Head-to-tail cyclization of LK7 peptide also resulted in a decrease in self-assembly of the LK7, an increase in binding affinity to the $A \beta_{40}$ peptide, and proteolytic stability in serum. This derivative also can stabilize the $A \beta_{40}$ secondary structure and inhibit $A \beta_{40}$-mediated cytotoxicity. Another derivative of LK7 peptide is Ac-LVFFARKHH-NH2 (LK7-HH), in which LK7 has been conjugated to the $\mathrm{HH}$ ligand as a chelator for reducing reactive oxygen species (ROS) production and capturing free and complexed ions of $\mathrm{Cu}^{2+}(57)$. This chelator also improved the anti-aggregate effects of LK7 on A $\beta$ peptide and reduced its self-aggregation properties.

Proline and aspartic acid were exchanged for valine and alanine, respectively, in $\operatorname{KVLFFA}(58,59)$. The derived peptide, referred to as 5 -mer iA 35 with sequence LPFFD, inhibited A $\beta$ aggregation, neurotoxicity, and reduced plaque load (58). Due to the lack of a proton on the secondary substituted nitrogen in the peptide bond of proline residue, it could inhibit the formation of the intramolecular hydrogen bonds into fibrils. Since these small peptides are prone to faster enzymatic degradation and have reduced BBB permeability in vivo, iA $35 p$ was modified by N-methylation between Pro and Phe residues to improve its stability (60). The results from in vitro and in vivo studies showed that it has the same inhibitory activity as the parental iA $\beta 5$ peptide against amyloid fibril formation and neurotoxicity but with improved protease resistance. Also, molecular dynamics 
simulations show that this peptide has more durable binding and enhanced activity against $A \beta_{40}$ aggregation in comparison to the $i A \beta 5$ peptide. In a similar study, the RIVFF sequence was produced by residue mutations of lysine16 (K) to arginine (R) and leucine17 (L) to isoleucine (I) on the KLVFF segment (61). The results indicated that this peptide could self-aggregate into $\beta$-sheet structures by reducing the surface tension of water and at higher concentrations $(>250 \mu \mathrm{M})$ enhanced the $A \beta$-induced cytotoxicity.

The peptide D-GRKKRRQRRR-GGGG-DVEFRH (A $\beta_{1-6}$ A2V-TAT) was investigated in vivo $(62,63)$. It was generated by modifying the $\mathrm{N}$-terminal fragment of ${ }^{1} \mathrm{DAEFRH}^{6}$ through mutation of alanine in position 2 to valine and conjugating with the HIV protein transduction domain GRKKRRQRRR (TAT). The resulting peptide showed strong anti-amyloidogenic effects in vitro and $A \beta$ aggregation inhibition in mouse models of Alzheimer's disease (64). The KLVFWAK motif was designed based on the ${ }^{16} \mathrm{KLVFFAE}^{22}$ sequence with mutations introduced at phenylalanine and glutamic acid residues to tryptophan and lysine respectively to enhance solubility and disrupt self-assembly via electrostatic repulsion. Results showed that the designed motif could only target the C-terminal region of $A \beta$ oligomers. The designed motif exhibited a lower self-aggregation tendency in comparison to other KLVFF-related sequences. Moreover, it demonstrated a higher binding affinity to $A \beta$ aggregates and fibrils than monomers (65).

RGKLVFFGR (OR1) and RGKLVFFGR-NH (OR2) are retro-inverso peptides (66), designed by the addition of arginine (R) and glycine $(G)$ to the KLVFF sequence. They exhibit high solubility and stability against enzymes. However, only the OR2 peptide showed inhibitory effects on $A \beta$ oligomer formation and cytotoxicity. OR2 was modified to HN-rGklvffGr-Ac (RI-OR2) by acetylation of the C-terminal residue (49). The result illustrated that the peptide has a high resistance to proteolysis, while maintaining the same inhibitory activity in vivo. In a follow-up study, the RI-OR2 peptide was attached to the TAT peptide to improve its permeability into cells and the BBB (48). The results showed the peptide was able to decrease $A \beta$ aggregation, plaque levels, and oxidative damages as well as increase the number of young neurons in the brain.

${ }^{31}$ IIGLMVGGVVIA ${ }^{42}$ and ${ }^{39}$ VVIA $^{42}$ sequences were designed based on the C-terminal domain of $A \beta_{42}(67)$. The ${ }^{39}$ VVIA $^{42}$ sequences could interact with $A \beta_{42}$ monomers and smaller oligomers at several sites, specifically at the N-terminal domain. At micromolar concentrations, the VVIA-NH 2 peptide inhibited $\mathrm{A} \beta_{42}$ aggregation, exhibited less toxicity, and protected synaptic activity. However, these effects were not observed for the acetylated Ac-VVIA sequence (68). The non-acetylated VVIA- $\mathrm{NH}_{2}$ sequence particularly interacts with the C-terminal domain while the Ac-VVIA peptide has a dispersed binding distribution (68). The $\mathrm{Ac}^{32}{ }^{32} \mathrm{ILMVG}^{37}-\mathrm{NH}_{2}$ sequence, a hexapeptide from the C-terminal fragment, has been shown to have a moderate efficacy with less toxicity (69).

O-acyl isopeptide and NMe-b-Ala26 (70) were derived from the full-length A $\beta$ sequence with modification of an ester bond at the Gly25-Ser26 moiety and an $\mathrm{N}$-methyl amide- $\beta$-Ala26, respectively. O-acyl isopeptide inhibited A $\beta_{42}$ fibrillation at equimolar concentrations through an inhibitory mechanism distinct from any other peptidic inhibitors reported previously. Also, this derivative was more soluble than $A \beta_{42}$ peptides and rapidly decomposed to $A \beta_{42}$ monomers under physiological conditions through an O-to- $\mathrm{N}$ acyl rearrangement reaction whereas NMe-b-Ala26 showed higher chemical stability at physiological conditions. 


\section{Non-A $\beta$-based peptide inhibitors}

Carnosine, a natural imidazole-containing dipeptide is a metal ion chelator (71). It inhibits the fibrillation and toxicity of amyloidogenic species such as glycated $\alpha$-Crystallin, $A \beta$ peptide, and prions. This peptide also inhibits the intramolecular salt bridge formation, which is vital to the stability and elongation of fibrils (71). Peptide D1, QSHYRHISPAQV (72), is another non-A $\beta$ peptide that reduces A $\beta$ aggregation and $A \beta$-associated cytotoxicity at high concentrations. N-methylated proprietary peptides such as $\mathrm{D}^{-\mathrm{NH}_{2}}$ (SEN304) and SEN1576 can inhibit A $\beta$-associated toxicity in vivo (73). Furthermore, SEN304 is a more potent inhibitor than customized versions of the KLVFF peptide. These peptides could interfere with the nucleation of $A \beta$, convert them into non-toxic forms, and eliminate toxic oligomers.

\section{PEPTIDE LIBRARY SCREENING}

There are many screening approaches to identify target-specific ligands $(74,75)$. Phage display is one such efficient high-throughput screening method that allows the screening of a wide variety of peptide libraries to identify specific peptide sequences against the desired target $(76,77)$. Wang et al. synthesized a linear peptide with sequence PYRWQLWWHNWS selected based on the screening of a randomized 12-mer peptide library against the target $A \beta_{1-10}$ sequence (78). After screening, specific phages were selected and their binding affinity to $A \beta_{1-10}$ was evaluated by real-time biomolecular interaction analysis. This peptide could specifically bind to $A \beta_{1-10}$, inhibit the aggregation of $A \beta$ into plaques, and reduce $A \beta_{1-42}$ induced-apoptosis. Furthermore, it illustrated a protective effect against $A \beta_{1-42}$-induced memory and learning impairments in animal models (59).

Larbanoix et al. utilized the phage display method to discover a linear hexapeptide against $A \beta_{1-42}$ aggregation (79). Two of the selected clones, Pepl: LIAIMA and Pep2: IFALMG, corresponding to fragment ${ }^{31}{ }^{I I G L M V}{ }^{36}$ from $A \beta_{1-42}$ peptide, demonstrated the highest binding affinities to $A \beta_{1-42}$ with Kd values in the micromolar range. Their specific interactions with $A \beta_{1-42}$ plaques were identified by immunohistochemistry on harvested brain tissue from an animal model of Alzheimer's disease. The peptides did not induce any toxicity in neurons in vitro. Moreover, the thioflavin $\mathrm{T}$ aggregation assay indicated that the designed peptides could suppress the amyloid fibril formation.

In 2010, a random heptapeptide library (XX-P-XXXX) on T7 phage was reported by Kawasaki et al. (80). The library was designed based on the LPFFD sequence XX-P-XXXX, where $\mathrm{P}$ is proline, and $\mathrm{X}$ is any amino acid. After the fifthround of biopanning against $A \beta_{1-42}$ soluble oligomers, eight new peptides containing arginine residues were obtained. The peptide with the strongest affinity to A $\beta$ (RGPRGRV) suppressed the formation of 37-48 kDa oligomers and maintained the monomeric form of $A \beta_{1-42}$ for up to $24 \mathrm{~h}$. In follow-up studies, to assess the effect of the peptide length on the inhibition of soluble oligomers formation, random libraries containing 3-residue and 4-residue peptides were prepared by phage display and evaluated. The results demonstrated that the 3-residue peptides could not significantly inhibit oligomers formation because of their 
smaller size. In contrast, the 4-residue peptide with the RFRK sequence inhibited the soluble oligomer formation like the heptapeptide (RGPRGRV). It also showed a slight decrease on $A \beta$ fibrillation (81), similar to the inhibitory activity of the N-Methylated Peptide (SEN304), against $A \beta_{42}$ aggregation $(25,82,83)$. TsujiUeno et al. utilized the all-steps-all-combinations (ASAC) method to explore $\mathrm{A} \beta_{42}$-binding peptide aptamers. The identified peptides from the primary and secondary libraries showed a weak binding affinity to $A \beta_{42}$ (Kd values in the $\mu \mathrm{m}$ range) (84). To further improve the peptide aptamers, Gautam et al. applied the mRNA display technique and paired-peptide library method. The library was assembled by a random shuffling method on selected peptide blocks taken from the formed primary and secondary peptide libraries by Tsuji-Ueno et al. (84). They reported two peptides with high binding affinity to $A \beta_{42}$ (Kd in the $n M$ range) which significantly inhibited the $A \beta_{42}$ aggregation (85). The improved peptide aptamers, P84 (CGILDPIPWGGSGGSCGILDPIPW) and P131 (GCPCIGIIGGSGGSDCSSDLTPS), where GGSGGS is the linker sequence, demonstrated a higher binding affinity for the $A \beta_{42}$ peptide (Kd values in the nanomolar range) compared to the primary and secondary $A \beta_{42}$-binding peptides (86). The results showed that both peptides could inhibit the $A \beta_{42}$ aggregation and result in the reduction of the cytotoxic effects of $A \beta_{42}$ fibrils and $A \beta_{42}$ oligomers in PC12 cells; P84 showed better efficacy than P131 on the cell line.

Groen and co-workers employed mirror-image phage display to identify selective and high-affinity D-peptide ligands for $A \beta_{1-42}$. The D-enantiomer $A \beta_{1-42}$ was used as a target for selection from a randomized 12- amino acid peptide library with more than 1 billion different peptides. After six rounds of biopanning, they identified a specific D-enantiomeric peptide, RPRTRLHTHRNR, called D3 (73). The D3 ligand inhibited $A \beta$ aggregation, and dissolved pre-formed $A \beta$ fibrils. Additionally, D3 ligand could disaggregate pre-existing amyloid plaques in the brain and result in an increase in the amount of $A \beta$ monomeric form, which has high clearance from the brain (87). FITC fluorescence data demonstrated that $A \beta-D 3$ clearance might have been associated with pericytes, which have a major role in the clearance of different $A \beta_{40 / 42}$ species $(88,89)$. Glial fibrillary acidic protein (GFAP) staining of astrocytes and CD1lb staining of microglia in brain sections revealed that the D3 significantly decreased the amount of plaque-related inflammation markers (active astrocytes and microglia) around the $A \beta$ plaques in comparison to the untreated animals. In addition to the anti-inflammatory properties, this peptide ligand could drastically reduce the $A \beta$ plaque load in brain tissue of transgenic APP-PSD mice after a 30-day treatment with administration of $9 \mathrm{mg}$ D3 per day per mouse. Computational simulation studies demonstrated strong electrostatic interactions between the arginine-rich D3 and negatively charged groups of $A \beta$ nonamer; D3 binding to $A \beta$ nonamer could change the topology of the $A \beta$ oligomers by inducing a twist in them and consequently promote the formation of $A \beta$ nonfibrillar aggregations $(73,90,91)$.

Luo et al. applied peptoid chemistry, N-substituted glycine oligomers as a class of peptidomimetics, to develop and improve selective high-affinity ligands for $A \beta_{42}$ (92). They constructed an on-bead peptoid library of 38,416 unique peptoids. After screening for $A \beta_{42}$-selective peptoid ligands, the IAM1 ligand and its dimeric form were selected and further evaluated. IAMl peptide showed about 10-fold more affinity for $A \beta_{42}$-binding than for $A \beta_{40}$, and inhibited $A \beta_{42}$ aggregation in vitro. The dimeric derivative (IAM1) $)_{2}$ demonstrated a 7.4-fold higher 
affinity for $\mathrm{A} \beta_{42}(60 \mathrm{nM})$ than the monomeric form. Moreover, (IAM1) 2 demonstrated neuroprotective effects on primary hippocampal neurons against $A \beta_{42^{-}}$ induced toxicity.

Due to the considerable similarities between the self-assembly of cyclic $d, 1-\alpha-$ peptides and amyloid structures, it is possible such peptides can bind to $A \beta$ nontoxic forms and stabilize them (29). Richman et al. described the cyclic peptide CP-2, cyclo-[l-J-w- H-s-K]s (J denotes l-norleucine), by screening a 6-residue library of head-to-tail cyclic d,l- $\alpha$-peptides consisting of residues Lys, Glu, Ser, Leu, Trp, and His using a one-bead-one-peptide combinatorial approach $(29,93)$. The selected peptide strongly interacted with $A \beta_{40} / A \beta_{42}$ and prevented their assembly, entirely disassembled $A \beta_{40}$ fibrils, and protected PC12 cells against $A \beta_{40} / A \beta_{42}$-induced toxicity, without having any toxic effects of its own. NMR spectroscopy revealed that the CP-2 peptide, in a self-assembled form, interacted with monomeric and low-oligomeric structures of $A \beta_{40}$ and induced weak $\alpha$-helix structures during the initial stage of $A \beta_{40}$ aggregation and subsequently promoted the conformational transition shift from a more toxic antiparallel $\beta$-sheet conformation to the less toxic parallel $\beta$-sheet.

In another study, Acerra et al. utilized an intracellular protein-fragment complementation assay (PCA) methodology for the screening of selective high-affinity peptides to $A \beta$ (94). The $A \beta_{25-35}$ sequence, known to self-assemble into toxic fibrils (95), was inserted into one half of the murine dihydrofolate reductase enzyme as a target, and the A $29-35$ sequence-based peptide was inserted on the other half of the enzyme (96). After the screening of primary and secondary libraries, two new targeting peptides L2P1, FSKATSN, and L2P2, PVKATTA were selected. These peptides shared no homology with the starting template $A \beta_{29-35}$. The results showed that all selected peptides could bind $A \beta_{42}$, inhibit fibril formation, and disaggregate pre-formed fibrils. To further improve the metabolic stability of selected peptides from primary and secondary libraries, their retro-inverso (RI) analogs were evaluated (86). All RI peptide ligands, such as KAR-Rl, L2P1a-RI, L2P1b-RI, L2P2a-RI, and L2P2b-RI, inhibited A $\beta$ fibrillation and disaggregated pre-formed fibrils, and reduced $A \beta_{42}$-induced toxicity in PC-12 cells.

\section{THE CURRENT STATE AND FUTURE DIRECTIONS OF A $\beta$ INHIBITORY PEPTIDES IN ALZHEIMER'S DISEASE}

A wide range of peptide-based inhibitors has been evaluated in cellular and animal models as new therapeutic compounds for inhibition of $A \beta$ aggregation. While experimental studies generated promising results, only a few of these inhibitory peptides have been successful enough to enter clinical trials. NAP or Davunetide peptide with NAPVSIPQ sequence, derived from the activitydependent neuroprotective protein (ADNP), was reported in 2003 by Gozes et al. (97). NAP was able to inhibit $A \beta$ aggregation, disassemble pre-formed fibrils, and protect the neuronal cells from $A \beta$ induced toxicity. Though NAP demonstrated benefits in phase II clinical trials for mild cognitive impairment, it failed in a phase III trial (98-100). PPI-1019 peptide (APAN), with a sequence of D-(H-[(Me-L)VFFL] $\mathrm{NH}_{2}$ ), is an N-methylated peptide which is derived from the D-enantiomeric 
Cholyl-LVFFA- $\mathrm{NH}_{2}$ that could inhibit $\mathrm{A} \beta$ aggregation and the induce toxicity in experimental studies (101). The phases I and II clinical trials of APAN was completed in patients with mild-moderate Alzheimer's disease in 2005 (NCT00100282, NCT00100334), but the outcome of this study is still unknown (https://clinicaltrials.gov/, last assessed 28 October 2020). Other reported inhibitory peptides including, D3 (102), D-Trp-Aib-OH (44), D-4F (36), TAT-R1-OR2 (48), NL-RIOR2-TAT90 (103), and R1-OR2 (49) have shown considerable efficacy in preclinical trials, but they have not yet entered clinical trials.

The reality is that, to date, there is no cure for Alzheimer's disease. Only optimism remains. Therefore, it is necessary to discover potential peptides for testing in clinical trials. The current inhibitory peptides have certain limitations such as poor BBB permeability and high cytotoxicity. To overcome these problems and further improve the inhibitory activity, a number of studies have focused on peptide-nanostructure conjugates (PNCs) approach that provides an opportunity to increase the capabilities of both these classes of materials $(55,104,105)$. Nanostructures could be considered as a potential vehicle to overcome poor BBB permeability and bring hope for neurodegenerative diseases therapy due to their size and various surface modifications (106). As an example, multivalent inhibitors can be developed against $A \beta$ aggregation by decorating gold nanoparticles with VVIA and LPFFD (107). The PNCs approach gives a fascinating insight into the fields of diagnosis and treatment, and provides new opportunities for the design of high-performance peptides $(108,109)$.

\section{CONCLUSION}

Despite a better understanding of the pathogenic mechanisms of Alzheimer's disease, finding efficient therapeutic compounds to prevent or halt the progression of Alzheimer's disease continues to be a challenge. A $\beta$ aggregation inhibition-based approaches are being developed with the aim to stop disease progression. While the reported inhibitory peptides have considerable advantages over other compounds, and experimental evidence has been encouraging, bench-to-bedside has not yet become a reality. Therefore, adequate knowledge of binding interactions of these peptides with their biological targets, the ligand-target complex, is required to design more accurate therapeutic biomolecules. Peptide inhibitors have unique properties, particularly, high selectivity, low accumulation in tissues, low side-effects and toxicity, and different chemical and biological synthesis routes when compared with other compounds. As researchers continue to focus on rational design, characterization, optimization, and interaction between the inhibitor and the $A \beta$ peptide complex, more peptide inhibitors are expected to succeed in clinical trials.

Conflict of Interest: The authors declare no potential conflicts of interest with respect to research, authorship and/or publication of this chapter.

Copyright and Permission Statement: We confirm that the materials included in this chapter do not violate copyright laws. Where relevant, appropriate permissions have been obtained from the original copyright holder(s). All original sources have been appropriately acknowledged and/or referenced. 


\section{REFERENCES}

1. 2009 Alzheimer's disease facts and figures. Alzheimer's \& Dementia. 2009;5(3):234-70. https://doi. org/10.1016/j.jalz.2009.03.001

2. 2018 Alzheimer's disease facts and figures. Alzheimer's Dementia. 2018;14(3):367-429. https://doi. org/10.1016/j.jalz.2018.02.001

3. Prince M, Comas-Herrera A, Knapp M, Guerchet M, Karagiannidou M. World Alzheimer report 2016: improving healthcare for people living with dementia: coverage, quality and costs now and in the future. Alzheimer's Disease International (ADI); London. 2016.

4. Bartus RT, Emerich DF. Cholinergic markers in Alzheimer disease. JAMA. 1999;282(23):2208-9. https://doi.org/10.1001/jama.282.23.2208

5. Mandelkow E-M, Mandelkow E. Tau in Alzheimer's disease. Trends Cell Biol. 1998;8(11):425-7. https://doi.org/10.1016/S0962-8924(98)01368-3

6. Finder VH, Glockshuber R. Amyloid- $\beta$ aggregation. Neurodegen Dis. 2007;4(1):13-27. https://doi. org/10.1159/000100355

7. Hardy J, Selkoe DJ. The amyloid hypothesis of Alzheimer's disease: Progress and problems on the road to therapeutics. Science. 2002;297(5580):353-6. https://doi.org/10.1126/science.1072994

8. Singh M, Singh S, Prasad S, Gambhir I. Nanotechnology in medicine and antibacterial effect of silver nanoparticles. Dig J Nanomater Biostruct. 2008;3(3):115-22.

9. Haass $C$, Selkoe DJ. Cellular processing of $\beta$-amyloid precursor protein and the genesis of amyloid $\beta$-peptide. Cell. 1993;75(6):1039-42. https://doi.org/10.1016/0092-8674(93)90312-E

10. Hall D, Edskes H. A model of amyloid's role in disease based on fibril fracture. Biophys Chem. 2009;145(1):17-28. https://doi.org/10.1016/j.bpc.2009.08.004

11. Hall D, Edskes H. Computational modeling of the relationship between amyloid and disease. Biophys Rev. 2012;4(3):205-22. https://doi.org/10.1007/s12551-012-0091-x

12. Liu H, Dong X, Liu F, Zheng J, Sun Y. Iminodiacetic acid-conjugated nanoparticles as a bifunctional modulator against $\mathrm{Zn} 2+-$ mediated amyloid $\beta$-protein aggregation and cytotoxicity. J Colloid Interf Sci. 2017;505:973-82. https://doi.org/10.1016/j.jcis.2017.06.093

13. Wang W, Han Y, Fan Y, Wang Y. Effects of gold nanospheres and nanocubes on amyloid- $\beta$ peptide fibrillation. Langmuir. 2019;35(6):2334-42. https://doi.org/10.1021/acs.langmuir.8b04006

14. Brahmachari S, Paul A, Segal D, Gazit E. Inhibition of amyloid oligomerization into different supramolecular architectures by small molecules: Mechanistic insights and design rules. Fut Med Chem. 2017;9(8):797-810. https://doi.org/10.4155/fmc-2017-0026

15. Jokar S, Khazaei S, Behnammanesh H, Shamloo A, Erfani M, Beiki D, et al. Recent advances in the design and applications of amyloid- $\beta$ peptide aggregation inhibitors for Alzheimer's disease therapy. Biophys Rev. 2019;11:1-25. https://doi.org/10.1007/s12551-019-00606-2

16. Rahimi F, Li H, Sinha S, Bitan G. Modulators of amyloid $\beta$-protein $(A \beta)$ self-assembly. Developing Therapeutics for Alzheimer's Disease. Elsevier; Boston. 2016. p. 97-191. https://doi.org/10.1016/ B978-0-12-802173-6.00006-X

17. Danho W, Swistok J, Khan W, Chu X-J, Cheung A, Fry D, et al. Opportunities and challenges of developing peptide drugs in the pharmaceutical industry. Peptides for Youth. Springer; New York. 2009. p. 467-9. https://doi.org/10.1007/978-0-387-73657-0_201

18. Bruno BJ, Miller GD, Lim CS. Basics and recent advances in peptide and protein drug delivery. Therap Deliv. 2013;4(11):1443-67. https://doi.org/10.4155/tde.13.104

19. Goyal D, Shuaib S, Mann S, Goyal B. Rationally designed peptides and peptidomimetics as inhibitors of amyloid- $\beta(A \beta)$ aggregation: Potential therapeutics of Alzheimer's disease. ACS Combinator Sci. 2017;19(2):55-80. https://doi.org/10.1021/acscombsci.6b00116

20. Jokar S, Behnammanesh H, Erfani M, Sharifzadeh M, Gholami M, Sabzevari O, et al. Synthesis, biological evaluation and preclinical study of a novel $99 \mathrm{mTc}$-peptide: A targeting probe of amyloid- $\beta$ plaques as a possible diagnostic agent for Alzheimer's disease. Bioorgan Chem. 2020;99:103857. https://doi.org/10.1016/j.bioorg.2020.103857

21. Lührs T, Ritter C, Adrian M, Riek-Loher D, Bohrmann B, Döbeli H, et al. 3D structure of Alzheimer's amyloid- $\beta$ (1-42) fibrils. Proc Natl Acad Sci. 2005;102(48):17342-7. https://doi.org/10.1073/ pnas. 0506723102 
22. Jokar S, Erfani M, Bavi O, Khazaei S, Sharifzadeh M, Hajiramezanali M, et al. Design of peptide-based inhibitor agent against amyloid- $\beta$ aggregation: Molecular docking, synthesis and in vitro evaluation. Bioorgan Chem. 2020;102:104050. https://doi.org/10.1016/j.bioorg.2020.104050

23. Reddy G, Straub JE, Thirumalai D. Influence of preformed asp23- lys 28 salt bridge on the conformational fluctuations of monomers and dimers of $A \beta$ peptides with implications for rates of fibril formation. J Phys Chem B. 2009;113(4):1162-72. https://doi.org/10.1021/jp808914c

24. Friedemann M, Helk E, Tiiman A, Zovo K, Palumaa P, Tõugu V. Effect of methionine-35 oxidation on the aggregation of amyloid- $\beta$ peptide. Biochem Biophys Rep. 2015;3:94-9. https://doi.org/10.1016/j. bbrep.2015.07.017

25. Li H, Du Z, Lopes DH, Fradinger EA, Wang C, Bitan G. C-terminal tetrapeptides inhibit A $\beta 42$ induced neurotoxicity primarily through specific interaction at the N-terminus of A $\beta 42$. J Med Chem. 2011;54(24):8451-60. https://doi.org/10.1021/jm200982p

26. Urbanc B, Cruz L, Yun S, Buldyrev SV, Bitan G, Teplow DB, et al. In silico study of amyloid $\beta$-protein folding and oligomerization. Proc Natl Acad Sci. 2004;101(50):17345-50. https://doi.org/10.1073/ pnas.0408153101

27. Liu J, Wang W, Zhang Q, Zhang S, Yuan Z. Study on the efficiency and interaction mechanism of a decapeptide inhibitor of $\beta$-amyloid aggregation. Biomacromolecules. 2014;15(3):931-9. https://doi. org/10.1021/bm401795e

28. Jagota S, Rajadas J. Synthesis of d-amino acid peptides and their effect on beta-amyloid aggregation and toxicity in transgenic Caenorhabditis elegans. Med Chem Res. 2013;22(8):3991-4000. https:// doi.org/10.1007/s00044-012-0386-2

29. Richman M, Wilk S, Chemerovski M, Wärmländer SK, Wahlström A, Gräslund A, et al. In vitro and mechanistic studies of an antiamyloidogenic self-assembled cyclic d, l- $\alpha$-peptide architecture. J Am Chem Soc. 2013;135(9):3474-84. https://doi.org/10.1021/ja310064v

30. Brener O, Dunkelmann T, Gremer L, Van Groen T, Mirecka EA, Kadish I, et al. QIAD assay for quantitating a compound's efficacy in elimination of toxic A $\beta$ oligomers. Sci Rep. 2015;5:13222. https:// doi.org/10.1038/srep13222

31. Leithold LH, Jiang N, Post J, Niemietz N, Schartmann E, Ziehm T, et al. Pharmacokinetic properties of tandem d-peptides designed for treatment of Alzheimer's disease. Eur J Pharmaceut Sci. 2016;89: 31-8. https://doi.org/10.1016/j.ejps.2016.04.016

32. Klein AN, Ziehm T, Tusche M, Buitenhuis J, Bartnik D, Boeddrich A, et al. Optimization of the all-D peptide D3 for A $\beta$ oligomer elimination. PLoS One. 2016;11(4):e0153035. https://doi.org/10.1371/ journal.pone.0153035

33. Zhang YX, Wang SW, Lu S, Zhang LX, Liu DQ, Ji M, et al. A mimotope of A $\beta$ oligomers may also behave as a $\beta$-sheet inhibitor. FEBS Lett. 2017;591(21):3615-24. https://doi.org/10.1002/1873-3468.12871

34. Granic I, Masman MF, Nijholt IM, Naude PJ, de Haan A, Borbély E, et al. LPYFDa neutralizes amyloid$\beta$-induced memory impairment and toxicity. J Alzheimers Dis. 2010;19(3):991-1005. https://doi. org/10.3233/JAD-2010-1297

35. Minicozzi V, Chiaraluce R, Consalvi V, Giordano C, Narcisi C, Punzi P, et al. Computational and experimental studies on $\beta$-sheet breakers targeting A $\beta 1-40$ fibrils. J Biol Chem. 2014;289(16):11242-52. https://doi.org/10.1074/jbc.M113.537472

36. Handattu SP, Garber DW, Monroe CE, van Groen T, Kadish I, Nayyar G, et al. Oral apolipoprotein AI mimetic peptide improves cognitive function and reduces amyloid burden in a mouse model of Alzheimer's disease. Neurobiol Dis. 2009;34(3):525-34. https://doi.org/10.1016/j.nbd.2009.03.007

37. Kino R, Araya T, Arai T, Sohma Y, Kanai M. Covalent modifier-type aggregation inhibitor of amyloid- $\beta$ based on a cyclo-KLVFF motif. Bioorgan Med Chem Lett. 2015;25(15):2972-5. https://doi. org/10.1016/j.bmcl.2015.05.027

38. Sohma Y. Medicinal chemistry focusing on aggregation of amyloid- $\beta$. Chem Pharmaceut Bull. 2016; 64(1):1-7. https://doi.org/10.1248/cpb.c15-00742

39. Luheshi LM, Hoyer W, de Barros TP, van Dijk Härd I, Brorsson A-C, Macao B, et al. Sequestration of the $A \beta$ peptide prevents toxicity and promotes degradation in vivo. PLoS Biol. 2010;8(3):e1000334.

40. Lin L-X, Bo X-Y, Tan Y-Z, Sun F-X, Song M, Zhao J, et al. Feasibility of $\beta$-sheet breaker peptide-H102 treatment for Alzheimer's disease based on $\beta$-amyloid hypothesis. PLoS One. 2014;9(11):e112052. https://doi.org/10.1371/journal.pone.0112052 
41. Sinopoli A, Giuffrida A, Tomasello MF, Giuffrida ML, Leone M, Attanasio F, et al. Ac-LPFFD-Th: A trehalose-conjugated peptidomimetic as a strong suppressor of amyloid- $\beta$ oligomer formation and cytotoxicity. ChemBioChem. 2016;17(16):1541-9. https://doi.org/10.1002/cbic.201600243

42. Wei C-W, Peng Y, Zhang L, Huang Q, Cheng M, Liu Y-N, et al. Synthesis and evaluation of ferrocenoyl pentapeptide (Fc-KLVFF) as an inhibitor of Alzheimer's A $\beta 1-42$ fibril formation in vitro. Bioorgan Med Chem Lett. 2011;21(19):5818-21. https://doi.org/10.1016/j.bmcl.2011.07.111

43. Pratim Bose P, Chatterjee U, Nerelius C, Govender T, Norstrom T, Gogoll A, et al. Poly-N-methylated amyloid $\beta$-peptide $(A \beta) C$-terminal fragments reduce $A \beta$ toxicity in vitro and in Drosophila melanogaster. J Med Chem. 2009;52(24):8002-9. https://doi.org/10.1021/jm901092h

44. Frydman-Marom A, Rechter M, Shefler I, Bram Y, Shalev DE, Gazit E. Cognitive-performance recovery of Alzheimer's disease model mice by modulation of early soluble amyloidal assemblies. Angewandte Chem. 2009;121(11):2015-20. https://doi.org/10.1002/ange.200802123

45. Tanaka F, Shibata K, Monobe Y, Akagi K-I, Masuda Y. Design and synthesis of $\beta$-strand-fixed peptides inhibiting aggregation of amyloid $\beta$-protein. Bioorgan Med Chem. 2020;28(18):115676. https://doi. org/10.1016/j.bmc.2020.115676

46. Horsley JR, Jovcevski B, Wegener KL, Yu J, Pukala TL, Abell AD. Rationally designed peptide-based inhibitor of A 442 fibril formation and toxicity: A potential therapeutic strategy for Alzheimer's disease. Biochem J. 2020;477(11):2039-54. https://doi.org/10.1042/BCJ20200290

47. Chorev M, Goodman M. Recent developments in retro peptides and proteins - An ongoing topochemical exploration. Trends Biotechnol. 1995;13(10):438-45. https://doi.org/10.1016/ S0167-7799(00)88999-4

48. Parthsarathy V, McClean PL, Hölscher C, Taylor M, Tinker C, Jones G, et al. A novel retro-inverso peptide inhibitor reduces amyloid deposition, oxidation and inflammation and stimulates neurogenesis in the APPswe/PS1 1 E9 mouse model of Alzheimer's disease. PLoS One. 2013;8(1):e54769. https:// doi.org/10.1371/journal.pone.0054769

49. Taylor M, Moore S, Mayes J, Parkin E, Beeg M, Canovi M, et al. Development of a proteolytically stable retro-inverso peptide inhibitor of $\beta$-amyloid oligomerization as a potential novel treatment for Alzheimer's disease. Biochemistry. 2010;49(15):3261-72. https://doi.org/10.1021/bi100144m

50. Loureiro JA, Crespo R, Börner H, Martins PM, Rocha FA, Coelho M, et al. Fluorinated beta-sheet breaker peptides. J Mater Chem B. 2014;2(16):2259-64. https://doi.org/10.1039/C3TB21483D

51. Luo J, Abrahams JP. Cyclic peptides as inhibitors of amyloid fibrillation. Chem A Eur J. 2014;20(9):2410-19. https://doi.org/10.1002/chem.201304253

52. Han X, He G. Toward a rational design to regulate $\beta$-amyloid fibrillation for alzheimer's disease treatment. ACS Chem Neurosci. 2018;9(2):198-210. https://doi.org/10.1021/acschemneuro.7b00477

53. Tjernberg LO, Näslund J, Lindqvist F, Johansson J, Karlström AR, Thyberg J, et al. Arrest of-amyloid fibril formation by a pentapeptide ligand. J Biol Chem. 1996;271(15):8545-8. https://doi. org/10.1074/jbc.271.15.8545

54. Matsunaga Y, Fujii A, Awasthi A, Yokotani J, Takakura T, Yamada T. Eight-residue A $\beta$ peptides inhibit the aggregation and enzymatic activity of A 442 . Regul Peptides. 2004;120(1-3):227-36. https://doi. org/10.1016/j.regpep.2004.03.013

55. Xiong N, Dong X-Y, Zheng J, Liu F-F, Sun Y. Design of LVFFARK and LVFFARK-functionalized nanoparticles for inhibiting amyloid $\beta$-protein fibrillation and cytotoxicity. ACS Appl Mater Interf. 2015;7(10):5650-62. https://doi.org/10.1021/acsami.5b00915

56. Zhang H, Dong X, Liu F, Zheng J, Sun Y. Ac-LVFFARK-NH2 conjugation to $\beta$-cyclodextrin exhibits significantly enhanced performance on inhibiting amyloid $\beta$-protein fibrillogenesis and cytotoxicity. Biophys Chem. 2018;235:40-7. https://doi.org/10.1016/j.bpc.2018.02.002

57. Zhang H, Zhang C, Dong XY, Zheng J, Sun Y. Design of nonapeptide LVFFARKHH: A bifunctional agent against $\mathrm{Cu} 2+-$ mediated amyloid $\beta$-protein aggregation and cytotoxicity. J Mol Recogn. 2018;31(6):e2697. https://doi.org/10.1002/jmr.2697

58. Soto C, Sigurdsson EM, Morelli L, Kumar RA, Castaño EM, Frangione B. $\beta$-sheet breaker peptides inhibit fibrillogenesis in a rat brain model of amyloidosis: Implications for Alzheimer's therapy. Nat Med. 1998;4(7):822-6. https://doi.org/10.1038/nm0798-822

59. Wood SJ, Wetzel R, Martin JD, Hurle MR. Prolines and aamyloidogenicity in fragments of the Alzheimer's peptide. beta./A4. Biochemistry. 1995;34(3):724-30. https://doi.org/10.1021/bi00003a003 
60. Cruz M, Tusell J, Grillo-Bosch D, Albericio F, Serratosa J, Rabanal F, et al. Inhibition of $\beta$-amyloid toxicity by short peptides containing N-methyl amino acids. J Peptide Res. 2004;63(3):324-8. https:// doi.org/10.1111/j.1399-3011.2004.00156.x

61. Ramaswamy K, Kumaraswamy P, Sethuraman S, Krishnan UM. Self-assembly characteristics of a structural analogue of Tjernberg peptide. RSC Adv. 2014;4(32):16517-23. https://doi.org/10.1039/ C3RA47754A

62. Cimini S, Sclip A, Mancini S, Colombo L, Messa M, Cagnotto A, et al. The cell-permeable A $\beta 1$ 6A2VTAT (D) peptide reverts synaptopathy induced by A 1 1-42wt. Neurobiol Dis. 2016;89:101-11. https://doi.org/10.1016/j.nbd.2015.12.013

63. Di Fede G, Catania M, Morbin M, Rossi G, Suardi S, Mazzoleni G, et al. A recessive mutation in the APP gene with dominant-negative effect on amyloidogenesis. Science. 2009;323(5920):1473-7. https://doi.org/10.1126/science.1168979

64. Di Fede G, Catania M, Maderna E, Morbin M, Moda F, Colombo L, et al. Tackling amyloidogenesis in Alzheimer's disease with A2V variants of Amyloid- $\beta$. Sci Rep. 2016;6:20949. https://doi.org/10.1038/ srep20949

65. Aoraha E, Candreva J, Kim JR. Engineering of a peptide probe for $\beta$-amyloid aggregates. Mol BioSyst. 2015;11(8):2281-9. https://doi.org/10.1039/C5MB00280J

66. Austen BM, Paleologou KE, Ali SA, Qureshi MM, Allsop D, El-Agnaf OM. Designing peptide inhibitors for oligomerization and toxicity of Alzheimer's $\beta$-amyloid peptide. Biochemistry. 2008;47(7):198492. https://doi.org/10.1021/bi701415b

67. Fradinger EA, Monien BH, Urbanc B, Lomakin A, Tan M, Li H, et al. C-terminal peptides coassemble into $A \beta 42$ oligomers and protect neurons against $A \beta 42$-induced neurotoxicity. Proc Natl Acad Sci. 2008;105(37):14175-80. https://doi.org/10.1073/pnas.0807163105

68. Zheng X, Wu C, Liu D, Li H, Bitan G, Shea J-E, et al. Mechanism of C-terminal fragments of amyloid $\beta$-protein as $A \beta$ inhibitors: Do C-terminal interactions play a key role in their inhibitory activity? J Phys Chem B. 2016;120(8):1615-23. https://doi.org/10.1021/acs.jpcb.5b08177

69. Bansal S, Maurya IK, Yadav N, Thota CK, Kumar V, Tikoo K, et al. C-terminal fragment, A $\beta 32-37$, analogues protect against a $\beta$ aggregation-induced toxicity. ACS Chem Neurosci. 2016;7(5):615-23. https://doi.org/10.1021/acschemneuro.6b00006

70. Kawashima H, Sohma Y, Nakanishi T, Kitamura H, Mukai H, Yamashita M, et al. A new class of aggregation inhibitor of amyloid- $\beta$ peptide based on an O-acyl isopeptide. Bioorgan Med Chem. 2013;21(21):6323-7. https://doi.org/10.1016/j.bmc.2013.08.062

71. Aloisi A, Barca A, Romano A, Guerrieri S, Storelli C, Rinaldi R, et al. Anti-aggregating effect of the naturally occurring dipeptide carnosine on aß1-42 fibril formation. PLoS One. 2013;8(7):e68159. https://doi.org/10.1371/journal.pone.0068159

72. Wiesehan K, Buder K, Linke RP, Patt S, Stoldt M, Unger E, et al. Selection of D-amino-acid peptides that bind to Alzheimer's disease amyloid peptide $A \beta 1-42$ by mirror image phage display. Chembiochem. 2003;4(8):748-53. https://doi.org/10.1002/cbic.200300631

73. Van Groen T, Wiesehan K, Funke SA, Kadish I, Nagel-Steger L, Willbold D. Reduction of Alzheimer's disease amyloid plaque load in transgenic mice by D3, A D-enantiomeric peptide identified by mirror image phage display. ChemMedChem. 2008;3(12):1848. https://doi.org/10.1002/cmdc.200800273

74. Biyani M, Nishigaki K, Biyani M. Biomolecular display technology: A new tool for drug discovery. Animal Biotechnology: Elsevier; 2014. p. 369-84. https://doi.org/10.1016/B978-0-12-416002-6.00020-1

75. Zwick MB, Shen J, Scott JK. Phage-displayed peptide libraries. Curr Opin Biotechnol. 1998;9(4): 427-36. https://doi.org/10.1016/S0958-1669(98)80017-7

76. Kang CK, Jayasinha V, Martin PT. Identification of peptides that specifically bind A $\beta 1-40$ amyloid in vitro and amyloid plaques in Alzheimer's disease brain using phage display. Neurobiol Dis. 2003;14(1):146-56. https://doi.org/10.1016/S0969-9961(03)00105-0

77. Smith GP. Filamentous fusion phage: Novel expression vectors that display cloned antigens on the virion surface. Science. 1985;228(4705):1315-17. https://doi.org/10.1126/science.4001944

78. Wang F, Zhou X-L, Yang Q-G, Xu W-H, Wang F, Chen Y-P, et al. A peptide that binds specifically to the $\beta$-amyloid of Alzheimer's disease: Selection and assessment of anti- $\beta$-amyloid neurotoxic effects. PLoS One. 2011;6(11):e27649. https://doi.org/10.1371/journal.pone.0027649 
79. Larbanoix L, Burtea C, Ansciaux E, Laurent S, Mahieu I, Vander Elst L, et al. Design and evaluation of a 6-mer amyloid-beta protein derived phage display library for molecular targeting of amyloid plaques in Alzheimer's disease: Comparison with two cyclic heptapeptides derived from a randomized phage display library. Peptides. 2011;32(6):1232-43. https://doi.org/10.1016/j.peptides.2011.04.026

80. Kawasaki T, Onodera K, Kamijo S. Selection of peptide inhibitors of soluble Aß1-42 oligomer formation by phage display. Biosci Biotechnol Biochem. 2010;74;2214-19. https://doi.org/10.1271/ bbb. 100388

81. Kawasaki T, Onodera K, Kamijo S. Identification of novel short peptide inhibitors of soluble 37/48 $\mathrm{kDa}$ oligomers of amyloid 342 . Biosci Biotechnol Biochem. 2011;75(8):1496-501. https://doi. org/10.1271/bbb. 110198

82. Kokkoni N, Stott K, Amijee H, Mason JM, Doig AJ. N-methylated peptide inhibitors of $\beta$-amyloid aggregation and toxicity. Optimization of the inhibitor structure. Biochemistry. 2006;45(32):9906-18. https://doi.org/10.1021/bi060837s

83. Zheng X, Liu D, Klärner F-G, Schrader T, Bitan G, Bowers MT. Amyloid $\beta$-protein assembly: The effect of molecular tweezers CLR01 and CLR03. J Phys Chem B. 2015;119(14):4831-41. https://doi. org/10.1021/acs.jpcb.5b00692

84. Tsuji-Ueno S, Komatsu M, Iguchi K, Takahashi M, Yoshino S, Suzuki M, et al. Novel high-affinity A $\beta$-binding peptides identified by an advanced in vitro evolution, progressive library method. Protein Peptide Lett. 2011;18(6):642-50. https://doi.org/10.2174/092986611795222678

85. Ghimire Gautam S, Komatsu M, Nishigaki K. Strong inhibition of beta-amyloid peptide aggregation realized by two-steps evolved peptides. Chem Biol Drug Design. 2015;85(3):356-68. https://doi. org/10.1111/cbdd.12400

86. Acerra N, Kad NM, Griffith DA, Ott S, Crowther DC, Mason JM. Retro-inversal of intracellular selected $\beta$-amyloid-interacting peptides: Implications for a novel Alzheimer's disease treatment. Biochemistry. 2014;53(13):2101-11. https://doi.org/10.1021/bi5001257

87. Tanzi R, Moir R, Wagner S. Clearance of Alzheimer's A $\beta$ peptide: The many roads to perdition. Neuron. 2004;43(5):605-8. https://doi.org/10.1016/S0896-6273(04)00533-1

88. Sagare AP, Bell RD, Zhao Z, Ma Q, Winkler EA, Ramanathan A, et al. Pericyte loss influences Alzheimer-like neurodegeneration in mice. Nat Commun. 2013;4(1):1-14. https://doi.org/10.1038/ ncomms3932

89. Ma Q, Zhao Z, Sagare AP, Wu Y, Wang M, Owens NC, et al. Blood-brain barrier-associated pericytes internalize and clear aggregated amyloid- $\beta 42$ by LRP1-dependent apolipoprotein E isoform-specific mechanism. Mol Neurodegen. 2018;13(1):1-13. https://doi.org/10.1186/s13024-018-0286-0

90. Funke SA, van Groen T, Kadish I, Bartnik D, Nagel-Steger L, Brener O, et al. Oral treatment with the D-enantiomeric peptide D3 improves the pathology and behavior of Alzheimer's disease transgenic mice. ACS Chem Neurosci. 2010;1(9):639-48. https://doi.org/10.1021/cn100057j

91. Funke SA, Willbold D. Mirror image phage display - A method to generate D-peptide ligands for use in diagnostic or therapeutical applications. Mol BioSyst. 2009;5(8):783-6. https://doi.org/10.1039/ b904138a

92. Luo Y, Vali S, Sun S, Chen X, Liang X, Drozhzhina T, et al. Aß42-binding peptoids as amyloid aggregation inhibitors and detection ligands. ACS Chem Neurosci. 2013;4(6):952-62. https://doi. org/10.1021/cn400011f

93. Lam KS, Salmon SE, Hersh EM, Hruby VJ, Kazmierski WM, Knapp RJ. A new type of synthetic peptide library for identifying ligand-binding activity. Nature. 1991;354(6348):82-4. https://doi. org/10.1038/354082a0

94. Remy I, Campbell-Valois F, Michnick SW. Detection of protein-protein interactions using a simple survival protein-fragment complementation assay based on the enzyme dihydrofolate reductase. Nature Protocols. 2007;2(9):2120. https://doi.org/10.1038/nprot.2007.266

95. Pike CJ, Walencewicz-Wasserman AJ, Kosmoski J, Cribbs DH, Glabe CG, Cotman CW. Structureactivity analyses of $\beta$-amyloid peptides: Contributions of the $\beta 25-35$ region to aggregation and neurotoxicity. J Neurochem. 1995;64(1):253-65. https://doi.org/10.1046/j.1471-4159.1995.64010253.x

96. Acerra N, Kad NM, Mason JM. Combining intracellular selection with protein-fragment complementation to derive A $\beta$ interacting peptides. Protein Eng Design Select. 2013;26(7):463-70. https://doi. org/10.1093/protein/gzt021 
97. Ashur-Fabian O, Segal-Ruder Y, Skutelsky E, Brenneman DE, Steingart RA, Giladi E, et al. The neuroprotective peptide NAP inhibits the aggregation of the beta-amyloid peptide. Peptides. 2003;24(9):1413-23. https://doi.org/10.1016/j.peptides.2003.08.005

98. Boxer AL, Lang AE, Grossman M, Knopman DS, Miller BL, Schneider LS, et al. Davunetide in patients with progressive supranuclear palsy: A randomised, double-blind, placebo-controlled phase 2/3 trial. Lancet Neurol. 2014;13(7):676-85. https://doi.org/10.1016/S1474-4422(14)70088-2

99. Matsuoka Y, Jouroukhin Y, Gray AJ, Ma L, Hirata-Fukae C, Li H-F, et al. A neuronal microtubuleinteracting agent, NAPVSIPQ, reduces tau pathology and enhances cognitive function in a mouse model of Alzheimer's disease. J Pharmacol Exp Therapeut. 2008;325(1):146-53. https://doi. org/10.1124/jpet.107.130526

100. Gozes I, Morimoto BH, Tiong J, Fox A, Sutherland K, Dangoor D, et al. NAP: Research and development of a peptide derived from activity-dependent neuroprotective protein (ADNP). CNS Drug Rev. 2005;11(4):353-68. https://doi.org/10.1111/j.1527-3458.2005.tb00053.x

101. Findeis MA. Peptide inhibitors of beta amyloid aggregation. Curr Topics Med Chem. 2002;2(4): 417-23. https://doi.org/10.2174/1568026024607508

102. Jiang N, Leithold LH, Post J, Ziehm T, Mauler J, Gremer L, et al. Preclinical pharmacokinetic studies of the tritium labelled D-enantiomeric peptide D3 developed for the treatment of Alzheimer s disease. PLoS One. 2015;10(6):e0128553. https://doi.org/10.1371/journal.pone.0128553

103. Gregori M, Taylor M, Salvati E, Re F, Mancini S, Balducci C, et al. Retro-inverso peptide inhibitor nanoparticles as potent inhibitors of aggregation of the Alzheimer's A $\beta$ peptide. Nanomed Nanotechnol Biol Med. 2017;13(2):723-32. https://doi.org/10.1016/j.nano.2016.10.006

104. Yang J, Liu W, Sun Y, Dong X. LVFFARK-PEG-stabilized black phosphorus nanosheets potently inhibit amyloid- $\beta$ fibrillogenesis. Langmuir. 2020;36(7):1804-12. https://doi.org/10.1021/acs. langmuir.9b03612

105. Hao S, Li X, Han A, Yang Y, Fang G, Liu J, et al. CLVFFA-functionalized gold nanoclusters inhibit aß40 fibrillation, fibrils' prolongation, and mature fibrils' disaggregation. ACS Chem Neurosci. 2019;10(11):4633-42. https://doi.org/10.1021/acschemneuro.9b00469

106. Niu X, Chen J, Gao J. Nanocarriers as a powerful vehicle to overcome blood-brain barrier in treating neurodegenerative diseases: Focus on recent advances. Asian J Pharmaceut Sci. 2019;14(5):480-96. https://doi.org/10.1016/j.ajps.2018.09.005

107. Xiong N, Zhao Y, Dong X, Zheng J, Sun Y. Design of a molecular hybrid of dual peptide inhibitors coupled on AuNPs for enhanced inhibition of amyloid $\beta$-protein aggregation and cytotoxicity. Small. 2017;13(13):1601666. https://doi.org/10.1002/smll.201601666

108. Jeong W-J, Bu J, Kubiatowicz LJ, Chen SS, Kim Y, Hong S. Peptide-nanoparticle conjugates: A next generation of diagnostic and therapeutic platforms? Nano Convergence. 2018;5(1):38. https://doi. org/10.1186/s40580-018-0170-1

109. Khafaji M, Zamani M, Golizadeh M, Bavi O. Inorganic nanomaterials for chemo/photothermal therapy: A promising horizon on effective cancer treatment. Biophys Rev. 2019;11(3):335-52. https://doi. org/10.1007/s12551-019-00532-3 